\title{
BMJ Open Prevalence and socioeconomic impact of depressive disorders in India: multisite population-based cross-sectional study
}

\author{
Banavaram Anniappan Arvind, ${ }^{1}$ Gopalkrishna Gururaj, ${ }^{2}$ Santosh Loganathan, ${ }^{3}$ \\ Senthil Amudhan, ${ }^{4}$ Mathew Varghese, ${ }^{5}$ Vivek Benegal, ${ }^{6}$ Girish N Rao, ${ }^{7}$ \\ Arun Mahadeo Kokane, ${ }^{8}$ Chavan B S, ${ }^{9}$ Dalal P K, ${ }^{10}$ Daya Ram, ${ }^{11}$ Kangkan Pathak, ${ }^{12}$ \\ Lenin Singh R K, ${ }^{13}$ Lokesh Kumar Singh, ${ }^{14}$ Pradeep Sharma, ${ }^{15}$ \\ Pradeep Kumar Saha, ${ }^{16}$ Ramasubramanian $C,{ }^{17}$ Ritambhara Y Mehta, ${ }^{18}$ \\ Shibukumar T M, ${ }^{19} \mathrm{NMHS}$ collaborators group
}

To cite: Arvind BA, Gururaj G, Loganathan S, et al. Prevalence and socioeconomic impact of depressive disorders in India: multisite population-based cross-sectional study. BMJ Open 2019;9:e027250. doi:10.1136/ bmjopen-2018-027250

- Prepublication history for this paper is available online. To view these files, please visit the journal online (http://dx.doi.org/ 10.1136/bmjopen-2018-027250

Received 13 October 2018 Revised 1 March 2019 Accepted 5 April 2019
Check for updates

(C) Author(s) (or their employer(s)) 2019. Re-use permitted under CC BY-NC. No commercial re-use. See rights and permissions. Published by BMJ.

For numbered affiliations see end of article.

Correspondence to Dr Gopalkrishna Gururaj; epiguru@yahoo.com

\section{ABSTRACT}

Objectives The National Mental Health Survey (NMHS) of India was undertaken with the objectives of (1) estimating the prevalence and patterns of various mental disorders in representative Indian population and (2) identifying the treatment gap, healthcare utilisation, disabilities and impact of mental disorders. This paper highlights findings pertaining to depressive disorders (DD) from the NMHS.

Design Multisite population-based cross-sectional study. Subjects were selected by multistage stratified random cluster sampling technique with random selection based on probability proportionate to size at each stage.

Setting Conducted across 12 states in India (representing varied cultural and geographical diversity), employing uniform, standardised and robust methodology.

Participants A total of 34802 adults ( $\geq 18$ years) were interviewed.

Main outcome measure Prevalence of depressive disorders (ICD-10 DCR) diagnosed using Mini International Neuropsychiatric Interview V.6.0

Results The weighted prevalence of lifetime and current DD was $5.25 \%$ (95\% Cl: $5.21 \%$ to $5.29 \%, \mathrm{n}=34802)$ and $2.68 \%$ (95\% Cl: $2.65 \%$ to $2.71 \%, \mathrm{n}=34802)$, respectively. Prevalence was highest in the $40-59$ age groups $(3.6 \%, n=10302)$, among females $(3.0 \%$, $\mathrm{n}=18217)$ and those residing in cities with population $>1$ million (5.2\%, $n=4244)$. Age, gender, place of residence, education and household income were found to be significantly associated with current DD. Nearly twothirds of individuals with DD reported disability of varying severity, and the treatment gap for depression in the study population was $79.1 \%$. On an average, households spent INR1500/month ( US\$ 23.0/month) towards care of persons affected with DD.

Conclusion Around 23 million adults would need care for DD in India at any given time. Since productive population is affected most, DD entails considerable socioeconomic impact at individual and family levels. This is a clarion call for all the concerned stakeholders to scale up services under National Mental Health Programme in India along with integrating care for DD with other ongoing national health programmes.

\section{Strengths and limitations of this study}

- National Mental Health Survey (NMHS) of India is the largest mental health survey conducted in India using standard, robust, uniform methodology (including uniform sample size, sampling technique and study instruments) across 12 states of India representing the cultural and geographical diversity of the country at one time period.

- NMHS provides information on prevalence, disability, treatment gap and socioeconomic impact associated with depressive disorders among adults in India.

- NMHS did not include children $<18$ years, homeless mentally ill individuals and those residing in mega cities (>10 million population).

\section{INTRODUCTION}

Depression is a common mental disorder cutting across age, gender and socioeconomic status in India and across the world. Globally, the burden of depression has been rising ${ }^{1}$ and major depressive disorder (DD) was the third leading cause of disability in $2015 .^{2}$ Estimated global prevalence of depressive episode/DD varies from $3.2 \%$ to $4.7 \% .^{34}$ The global pooled period prevalence of mood disorders was $5.4 \%,{ }^{5}$ and its prevalence in WHO-World Mental Health Survey ranged from $0.8 \%$ to $9.6 \%$ across countries. ${ }^{6}$ By 2030, unipolar depression is predicted to be the second leading contributor to the global burden of disease. ${ }^{7}$ Burden of depression is further amplified by its 'cause and consequence' relationship with many non communicable diseases (NCDs) ${ }^{89}$ and thus has a huge impact on individuals, families and societies.

Depression is one of the most commonly diagnosed mental disorders in primary care settings. ${ }^{10-12}$ In India, it is estimated that 
nearly one-third of patients seeking help from healthcare facilities could have symptoms related to depression, and the crude prevalence rate of mood disorder was estimated to vary from as low as 0.5 to as high as 78 per 1000 population. ${ }^{13}$ Previous epidemiological studies on depression in India have been conducted using differing methodologies, sample sizes, sampling techniques, study instruments, case definitions and on different study populations at different time periods. ${ }^{13-16}$ Thus, reliable state and national level estimates of depression prevalence are not available for the country.

Evidence-based interventions and cost-effective treatment options are available to reduce the burden of depression, ${ }^{17} 18$ and the failure to implement them can have considerable socioeconomic impact at both household and national levels. ${ }^{19}$ The National Mental Health Policy and National Mental Health Programme of India (NMHP) optimistically envisions reducing the burden of mental illness including depression by providing accessible, affordable and quality health and social care within a rights-based framework. ${ }^{20}{ }^{21}$ With a need for good quality data to plan, programme, finance and deliver mental health services, a large-scale population-based National Mental Health Survey (NMHS) was undertaken to provide reliable evidence to strengthen mental health programme in India. The present paper describes the prevalence, characteristics, treatment gap and socioeconomic impact of DD in the Indian adult population, based on the findings from NMHS. ${ }^{22} 23$

\section{METHODS}

The NMHS was a multisite population-based study conducted across 12 Indian states during 2015-2016 using a uniform, standardised and robust methodology. The detailed methodology of the NMHS is available at (http://indianmhs.nimhans.ac.in/nmhs-reports. php) and elsewhere ${ }^{24}$ with only a brief summary being presented in this paper. A National Technical Advisory Group and a National Expert Panel comprising subject experts from varied disciplines steered the NMHS. The National Institute of Mental Health and Neuro Sciences (NIMHANS) Institutional Ethics Committee provided ethical clearance and the participating states also obtained ethical clearance from their respective Institutional Review Boards.

States representing different geographical areas and the cultural diversity of India were selected for the NMHS, so as to be able to generate state level and pooled national estimates of the prevalence of mental disorders, including DD. Selection of partner institutions in the identified states for conducting NMHS was contingent on the presence of experts in mental health and public health disciplines at these sites, a previous record of conducting large-scale surveys, representation of different geographical regions as well as the availability of diagnostic tools in the concerned regional language. An NMHS pilot study, undertaken in the Kolar district, of the southern
Indian state of Karnataka, helped to refine and finalise the methodology and logistical planning for the conduct of a larger national survey (unpublished report).

Utilising standard statistical procedures used for sample size estimation in population-based surveys, it was determined to interview 3000 adult ( $\geq 18$ years of age) respondents in each state with a total of 36000 adults from 12 states. The survey adopted a multistage, stratified, random cluster sampling technique, with random selection based on probability proportionate to size at each stage. As per the Census of India 2011, ${ }^{25}$ each named inhabited village and ward constituted a rural and an urban cluster, respectively. Urban areas were categorised as cities with less than one million population and cities with population $>1$ million. All inhabited households within the selected clusters were listed and numbered serially to form the sampling frame for subsequent selection of households through systematic random sampling. Primary respondents of the households selected for survey were interviewed after obtaining informed consent to collect sociodemographic information of all the individual members who were ordinarily residing for a minimum period of 6 months. Temporary visitors/visiting relatives who were not members of the selected households were excluded. All the eligible respondents (individuals aged $>18$ years) were interviewed using the standard set of study instruments. In case an eligible member was not available even after three visits, he/she was declared a nonresponder.

The Mini International Neuropsychiatric Interview (MINI) schedule V. $6^{26}$ was used for diagnosing psychiatric disorders, including DD in the study population. The MINI is a structured psychiatric diagnostic instrument widely used in epidemiological studies. It is short, simple, reliable, easy to administer and is also available in multiple Indian languages. It is also available on electronic data-entry platforms with built-in diagnostic algorithms generating diagnoses compatible with the International Classification of Diseases, tenth revision (ICD-10) and Diagnostic and Statistical Manual of Mental Disorders, fourth edition (DSM-IV).

Disability owing to mental disorders, including DD across three dimensions of work, social and family life was assessed using the Sheehan disability scale, which is compatible with and present on the MINI platform. ${ }^{27}$ A separate set of validated questions was used to assess the health treatment, care seeking pattern and socioeconomic impact associated with DD. All study instruments used in NMHS were validated at four levels viz. at NIMHANS with clinical subjects in outpatient settings, during the pilot study, before initiation of the main study and during the survey through re-interview of $5 \%$ of the interviewed sample by the respective state team. Leveraging information technology, NMHS adopted computer-assisted personal interviews that were found to be faster, reliable, valid, cost-effective and easier to monitor the data collection process, when compared with traditional paper and pencil Instruments. 
In all, 104 field data collectors with a background in psychology/social work/sociology/rural development or related areas were recruited for data collection purposes in 12 states. These personnel were systematically and rigorously trained over a period of 7-8 weeks, based on the principles of adult learning and through 'observelearn-practice-demonstrate' method, on administering the study instruments and other aspects of survey methodology using a specifically designed training schema for the survey. ${ }^{22}$

A robust three-tier monitoring mechanism was deployed at field, state and central levels to ensure collection of good quality data. These included spot checks, supervisory field visits and weekly and monthly review meetings. Re-interviews were conducted on $5 \%$ of the original interviews. Data collected in each state were periodically transferred onto a dedicated server maintained at NIMHANS. The collected data were checked for errors, cleaned and compiled to form the final edited dataset. Diagnosis of DD was done on the basis of ICD-10, diagnostic criteria for research. In the present study, DD is defined to include mild to moderate depression, severe depression with/ without psychosis and recurrent depressive episodes. Current prevalence corresponds to the presence of DD within previous 2 weeks of the survey.

Considering unequal probability of selection and non-response rate, weighted prevalence estimates were derived for DD. All estimates are presented with 95\% CIs. Multiple logistic regression analysis was undertaken considering DD as the dependent variable and sociodemographic characteristics (like gender, age, place of residence, education, employment status, marital status and household income quintile) as the independent variables for identifying factors associated with DD. Adjusted odds ratios calculated using the model reflected the risk of having DD for each of the selected group of participants against the risk in the reference group. In addition, analysis on co-occurrence of other diagnostic categories of MINI (schedule V.6.0) among individuals with DD was undertaken. SPSS V.22. $0^{28}$ was used for all analyses.

\section{Patient and public involvement}

This research was done without patient and public involvement. Patients and public were not invited to comment on the study design and were not consulted to develop patient-relevant outcomes or interpret the results. Patients were not invited to contribute to the writing or editing of this document for readability or accuracy.

\section{RESULTS}

Overall 10610 households were contacted in 12 states of India, and among them 9666 households were surveyed (household response rate 91.1\%) during 2015-2016. A total of 39532 eligible adults $>18$ years were contacted, and 34802 adults were interviewed (individual response rate-88.0\%). Respondents in the age group of 18-29 years constituted $34.0 \%$ of the study population. Females represented $52.3 \%$ and $68.8 \%$ of the study subjects were from rural areas. Nearly three-fourth of the study subjects were married, and the proportion of 'not literate' was $24.3 \%$.

The overall weighted prevalence of lifetime DD was $5.25 \%$ (95\% CI: 5.21 to 5.29 ) and it varied across the sociodemographic groups. The lifetime prevalence of DD was relatively high in $40-49$ age group $(7.47 \%)$ and marginally more in females (5.72\%) when compared with males $(4.75 \%)$. The lifetime prevalence of DD was also higher among those residing in cities with population $>1$ million $(8.23 \%)$, belonging to the lowest income quintile group $(6.36 \%)$ and among those who were widowed/ divorced/separated (11.23\%) (table 1).

The current prevalence of DD was $2.68 \%$ (95\% CI: 2.65 to 2.71 ) in the study population and was higher in $40-59$ years age group (3.6\%) (figure 1). In comparison with males, current prevalence in females remained high across all age groups, except in 30-39 years (figure 1). The prevalence of current DD in the cities with population $>1$ million $(5.17 \%)$ was nearly two and a half times as high as the prevalence in rural area $(2.15 \%)$ or cities with population of $<1$ million $(1.90 \%)$. Respondents with lower level of education (not literate: $3.63 \%$, education up to primary school: $3.11 \%$ ) and belonging to lower economic strata (lowest income quintile $3.42 \%$, second lowest income quintile $3.14 \%$ ) had higher prevalence. Current prevalence rate among widowed/divorced/separated $(5.23 \%)$ was two to three times as high as the prevalence among those married $(2.75 \%)$ and never married $(1.70 \%)$ (table 1).

Among the states, prevalence of current DD varied from $1.2 \%$ in Gujarat to as high as $4.7 \%$ in Jharkhand. Prevalence in Jharkhand (4.7\%), Tamil Nadu (4.5\%), West Bengal (4.3\%) and Manipur (3.7\%) was above the national prevalence rate. Similarly, the lifetime prevalence of DD varied widely across states, ranging from $1.9 \%$ in Gujarat to $12.6 \%$ in Tamil Nadu.

In the final multiple logistic regression analysis, age, gender, place of residence, education and household income were found to be significantly associated with current DD. The middle-aged productive population (40-59years) was at two times higher odds of having current DD when compared with 18-29 age group, and females were $23 \%$ more likely to have current DD in comparison to males. Residents of cities with population $>1$ million had three times higher odds of having current DD in comparison with rural residents. Lower levels of education and belonging to poor households were significantly associated with the occurrence of DD. Not being literate had 2.1 times higher odds of having current DD compared with professionals, and individuals belonging to lowest household income quintile, compared with highest income quintile group, were $93 \%$ more likely to have current DD (table 2).

DD is a major contributor to the overall mental morbidity in India with one-fourth of the proportional mental morbidity being attributed to DD. ${ }^{22}$ Among the 
Table 1 Distribution of depressive disorders among adults by sociodemographic characteristics

\begin{tabular}{|c|c|c|c|}
\hline \multirow{2}{*}{\multicolumn{2}{|c|}{ Sociodemographic characteristics }} & \multicolumn{2}{|c|}{ Prevalence of depressive disorders } \\
\hline & & \multirow{2}{*}{$\begin{array}{l}\begin{array}{l}\text { Current } \\
\%(95 \% \mathrm{Cl})\end{array} \\
2.68(2.65 \text { to } 2.71)\end{array}$} & \multirow{2}{*}{$\begin{array}{l}\text { Lifetime } \\
\% \text { (95\% Cl) } \\
5.25 \text { (5.21 to } 5.29)\end{array}$} \\
\hline & Total & & \\
\hline \multirow[t]{3}{*}{ Residence } & Rural & 2.15 (2.12 to 2.18$)$ & 4.48 (4.42 to 4.51$)$ \\
\hline & Cities with population $<1$ million & 1.90 (1.84 to 1.96$)$ & 4.93 (4.82 to 5.01$)$ \\
\hline & Cities with population $>1$ million & 5.17 (5.08 to 5.25$)$ & 8.23 (8.11 to 8.33$)$ \\
\hline \multirow[t]{6}{*}{ Education } & Illiterate (no formal education) & 3.63 (3.57 to 3.70$)$ & $6.04(5.95$ to 6.11$)$ \\
\hline & Primary (first to fifth std) & 3.11 (3.04 to 3.18$)$ & 5.76 (5.67 to 5.85$)$ \\
\hline & Secondary (sixth to seventh std) & 2.70 (2.63 to 2.77$)$ & 5.86 (5.76 to 5.96$)$ \\
\hline & High school (eighth to tenth std) & 2.26 (2.20 to 2.33$)$ & 4.67 (4.57 to 4.76$)$ \\
\hline & PreUniversity/Nocational & 1.61 (1.54 to 1.68$)$ & 3.20 (3.11 to 3.29$)$ \\
\hline & Graduate/Post graduate/Professional & 1.37 (1.30 to 1.42$)$ & 4.49 (4.38 to 4.59$)$ \\
\hline \multirow[t]{2}{*}{ Occupation } & Working & 2.70 (2.66 to 2.74$)$ & $5.56(5.50$ to 5.61$)$ \\
\hline & Not working & 2.66 (2.62 to 2.70$)$ & 5.00 (4.95 to 5.05$)$ \\
\hline \multirow[t]{3}{*}{ Marital Status } & Never married & $1.70(1.65$ to 1.75$)$ & 2.87 (2.80 to 2.93$)$ \\
\hline & Married & 2.75 (2.72 to 2.79$)$ & 5.44 (5.39 to 5.48$)$ \\
\hline & Widowed/Divorced/Separated & 5.23 (5.06 to 5.39$)$ & 11.23 (10.98 to 11.45$)$ \\
\hline \multirow[t]{5}{*}{ Income quintile } & Lowest & 3.42 (3.35 to 3.50$)$ & $6.36(6.25$ to 6.45$)$ \\
\hline & Second & 3.14 (3.07 to 3.21$)$ & 5.68 (5.58 to 5.77$)$ \\
\hline & Middle & 2.89 (2.82 to 2.95$)$ & 5.42 (5.32 to 5.50$)$ \\
\hline & Fourth & 2.20 (2.14 to 2.26$)$ & 4.21 (4.13 to 4.29$)$ \\
\hline & Highest & 1.91 (1.86 to 1.96$)$ & 4.76 (4.68 to 4.84$)$ \\
\hline
\end{tabular}

individuals with current DD, nearly $40 \%$ were diagnosed as having severe depression. Similarly, co-occurring mental disorder (commonly neurotic/stress related disorder and substance use disorder) was observed in nearly $50 \%$ of the individuals with current DD.

Disability and socioeconomic impact were assessed among subjects with exclusive diagnosis of current DD. DD entails considerable disability with slightly over two-thirds of persons with DD reporting disability of varying severity at work $(67.3 \%)$, in social $(68.6 \%)$ and family life $(70.2 \%)$, and $20.9 \%$ reported significant difficulty in carrying out activities of daily living. Such difficulty in activities of daily living was present for a median of 20 days in previous 1 month of the survey period. On an average, INR 1500 per month (about USD 23.0/month) was reportedly spent by the family members towards care of a person with current DD, which includes costs towards treatment, consultation and transportation (table 3).

The treatment gap for current DD (defined as proportion of individuals diagnosed with current DD and not on any treatment with a formal/trained healthcare provider) in the study population was $79.1 \%$ and varied by gender (more in females-80.1\%), income levels (higher in lower economic strata-81.0\%), place of residence (more in cities with $<1$ million

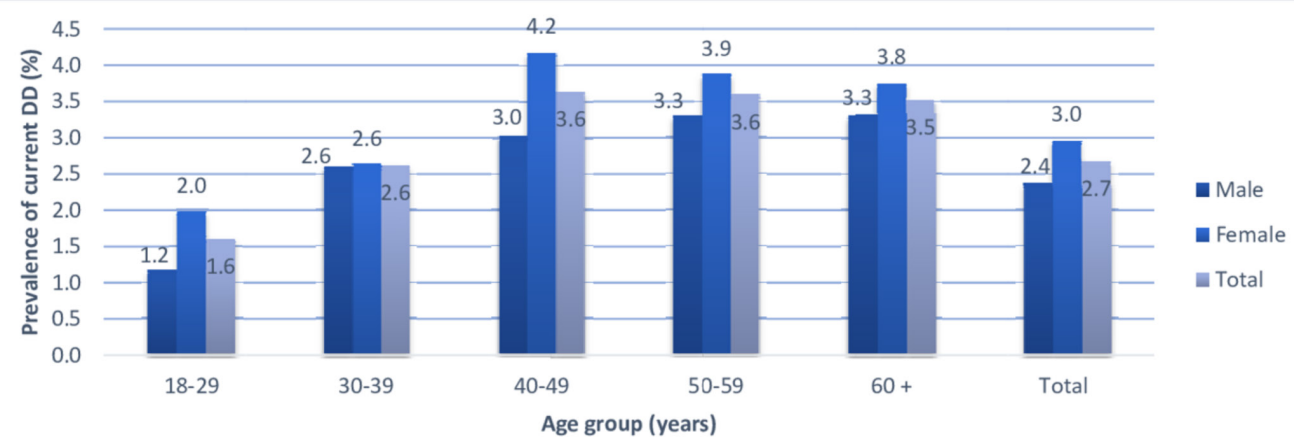

Figure 1 Prevalence of current DDs among adults (>18 years) in India by age and gender. DD, depressive disorder. 
Table 2 Multiple logistic regression analysis for factors associated with current depressive disorder among adults in India: NMHS 2016

\begin{tabular}{|c|c|c|c|}
\hline & Adjusted OR & $95 \% \mathrm{Cl}$ & $P$ value \\
\hline \multicolumn{4}{|l|}{ Gender } \\
\hline Male (ref) & 1.0 & & - \\
\hline Female & 1.23 & (1.04 to 1.45$)$ & 0.016 \\
\hline \multicolumn{4}{|l|}{ Age } \\
\hline $18-29$ (ref) & 1.0 & & - \\
\hline $30-39$ & 1.45 & (1.16 to 1.82$)$ & 0.001 \\
\hline $40-49$ & 1.93 & (1.53 to 2.42$)$ & $<0.001$ \\
\hline $50-59$ & 1.87 & (1.46 to 2.39$)$ & $<0.001$ \\
\hline$\geq 60$ & 1.72 & (1.34 to 2.21$)$ & $<0.001$ \\
\hline \multicolumn{4}{|l|}{ Marital status } \\
\hline Never married (ref) & 1.0 & & - \\
\hline Married & 0.95 & (0.75 to 1.21$)$ & 0.667 \\
\hline Widowed/divorced/separated & 1.33 & (0.95 to 1.87$)$ & 0.099 \\
\hline \multicolumn{4}{|l|}{ Residence } \\
\hline Rural (ref) & 1.0 & & - \\
\hline Cities with population of $<1$ million & 0.99 & (0.80 to 1.25$)$ & 0.995 \\
\hline Cities with population $>1$ million & 3.06 & (2.63 to 3.55$)$ & $<0.001$ \\
\hline \multicolumn{4}{|l|}{ Education } \\
\hline Graduate and above (ref) & 1.0 & & \\
\hline Illiterate & 2.14 & (1.56 to 2.94$)$ & $<0.001$ \\
\hline Primary school & 1.88 & (1.38 to 2.58$)$ & $<0.001$ \\
\hline Middle school & 1.88 & (1.36 to 2.59$)$ & $<0.001$ \\
\hline High school & 1.58 & (1.14 to 2.19$)$ & 0.006 \\
\hline Preuniversity/vocational courses & 1.29 & (0.89 to 1.88$)$ & 0.175 \\
\hline \multicolumn{4}{|l|}{ Employment status } \\
\hline Working (ref) & 1.0 & & - \\
\hline Not working & 0.87 & (0.74 to 1.03$)$ & 0.096 \\
\hline \multicolumn{4}{|l|}{ Household Income } \\
\hline Highest income quintile (ref) & 1.0 & & - \\
\hline Lowest income quintile & 1.93 & (1.54 to 2.42$)$ & $<0.001$ \\
\hline Second lowest income quintile & 1.75 & (1.40 to 2.19$)$ & $<0.001$ \\
\hline Middle income quintile & 1.57 & (1.26 to 1.96$)$ & $<0.001$ \\
\hline Fourth income quintile & 1.15 & (0.91 to 1.45$)$ & 0.252 \\
\hline
\end{tabular}

NMHS, National Mental Health Survey.

population-87.3\%) and across states. Though there was not much difference in the treatment gap across different age groups, treatment gap was slightly high among $60+$ individuals $(81.0 \%)$. Among individuals currently on treatment for DD, the median duration of being on treatment was 24 months with psychiatrists and general practitioners being the major care providers for most subjects. Few respondents had sought care from AYUSH (Ayurveda, Unani, Siddha and Homeopathy) practitioners and priest/religious healers. Though the reported median duration of illness was 36 months, the duration of being on treatment was 24 months indicating a missed opportunity of 12 months for care provision (table 4).

\section{DISCUSSION}

The NMHS 2015-2016 is one of the largest population-based survey conducted in India to assess the burden of mental disorders in a comprehensive manner using robust methodology. The study was conducted across 12 states during one time period, using uniform 
Table 3 Disability and socioeconomic impact associated with current depressive disorder among adults in India: NMHS 2016

\begin{tabular}{|c|c|}
\hline Characteristics & $\mathbf{N}(\%)$ \\
\hline \multicolumn{2}{|l|}{ Self-reported disability $(n=325)$} \\
\hline Any disability & $254(78.15)$ \\
\hline Work life & $218(67.28)$ \\
\hline Social life & $223(68.61)$ \\
\hline Family life & $228(70.15)$ \\
\hline \multicolumn{2}{|l|}{ Difficulties with activities of daily life $(n=325)$} \\
\hline Could do as usual & $157(48.30)$ \\
\hline Could do but not everything & $100(30.76)$ \\
\hline Could do only something & $44(13.53)$ \\
\hline Extreme or could do nothing & $24(7.38)$ \\
\hline \multicolumn{2}{|l|}{ Socioeconomic impact } \\
\hline $\begin{array}{l}\text { Median number of days with difficulty in } \\
\text { carrying out daily activities in the past } \\
30 \text { days }(n=192)\end{array}$ & 20 \\
\hline $\begin{array}{l}\text { Median number of days family members } \\
\text { were not able to go to work in the past } \\
3 \text { months for care of patient }(n=42)\end{array}$ & 8.5 \\
\hline $\begin{array}{l}\text { Median number of days family leisure or } \\
\text { social activities was missed }(n=92)\end{array}$ & 10 \\
\hline Median monthly expenditure in USD $(n=47)$ & $\sim 23$ \\
\hline
\end{tabular}

NMHS, National Mental Health Survey.

methodology, sampling technique, sample size and study instruments. Notably, field data collectors were of similar background and underwent uniform training in all the study sites. Robust supervision and monitoring mechanism were strictly implemented. Thus, by overcoming the limitations of the previous epidemiological studies, NMHS provides accurate estimates of burden of DD both at state and national levels.

The lifetime and current prevalence of DD in India was estimated at $5.25 \%$ and $2.68 \%$, respectively, and the prevalence varied across the 12 NMHS states. The observed lifetime and current prevalence of DD in India is comparatively lower than the global estimates. Meta-analysis, of studies conducted across globe, reported the aggregate lifetime prevalence of depression as $10.8 \% .^{29}$ The lifetime prevalence estimate of major depression is observed to vary widely across countries, with prevalence generally higher in high income versus low-middle income countries. ${ }^{30} 31$ The average lifetime prevalence estimates of DSM-IV Major depressive episode were $14.6 \%$ in the 10 high income countries and $11.1 \%$ in 8 low to middle income countries. ${ }^{32}$ The global 12 -month prevalence of depressive episode (3.2\%), DD (4.4\%) and point prevalence of major depressive disorder $(4.7 \%)$ were higher when compared with current prevalence of DD in NMHS. ${ }^{3433} 34$ The average 12-month prevalence estimates of DSM-IV major depressive episode was $5.5 \%$ in the 10 high income and $5.9 \%$ in the 8 low to middle income countries. ${ }^{32}$ However, Ustun et al (2004) have observed the 12-month prevalence of major depressive episodes in south east Asia region to be $2.96 \%$ among females and $1.74 \%$ among males. ${ }^{35}$

The lower prevalence estimate of DD in NMHS resonates with estimates from other large population-based studies conducted in India. The multisite epidemiological study conducted in India as part of the world mental health survey has reported mood (depressive) disorder (12-month) prevalence of $1.44 \% .^{36}$ Similarly, a study conducted in a large city in India has observed the lifetime and 12-month prevalence of depression to be $3.14 \%$ and $1.75 \%$, respectively. ${ }^{37}$ However, prevalence of major depressive disorder in a study conducted in rural area of south India was $6.62 \% .^{38}$ Several factors including sociocultural factors are known to influence the occurrence of depression, and the differential distribution of these factors across regions could probably explain the lower prevalence of current DD in India and also the variation across states in NMHS. ${ }^{39-41}$ In addition, varied definitions of depression, different diagnostic tool used to ascertain depression and the reference period for current prevalence could also contribute to the variation in prevalence between the present finding and the studies conducted in India and globally. The current prevalence of DD in NMHS corresponds to prevalence in the previous 2 weeks of the survey period, which we consider as the most reliable point estimate as it is less

Table 4 Treatment gap and care characteristics of depressive disorder among adults in India: NMHS 2016

\begin{tabular}{|c|c|c|c|c|c|c|}
\hline $\begin{array}{l}\text { Treatment gap and care characteristics } \\
\text { of depressive disorder }\end{array}$ & Overall $(n=330)$ & $\begin{array}{l}\text { Male } \\
(n=79)\end{array}$ & $\begin{array}{l}\text { Female } \\
(n=251)\end{array}$ & $\begin{array}{l}\text { Rural } \\
(n=237)\end{array}$ & $\begin{array}{l}\text { Urban non- } \\
\text { metro } \\
(n=55)\end{array}$ & $\begin{array}{l}\text { Urban metro } \\
(\mathrm{n}=38)\end{array}$ \\
\hline Treatment gap & $79.1 \%$ & $75.9 \%$ & $80.1 \%$ & $78.1 \%$ & $87.3 \%$ & $73.7 \%$ \\
\hline Median duration of illness (in months) & $36(1-480)$ & 24 & 36 & 36 & 30 & 36 \\
\hline $\begin{array}{l}\text { Median interval between onset of illness } \\
\text { and consultation (in months) }\end{array}$ & $3(1-120)$ & 3 & 3.5 & 4 & 1 & 3 \\
\hline
\end{tabular}

NMHS, National Mental Health Survey. 
affected by recall bias when compared with 12-month prevalence of DD.

The prevalence of DD in India is several fold higher when compared with communicable diseases like tuberculosis $^{42}$ and HIV/AIDS. ${ }^{43}$ The NMHS has estimated that at any given point, nearly 23 million adults in India would require care for DD. Under each District Mental Health Programme (average population of the Indian district being 1.5-2.0 million), the implementation arm of NMHP, 25 000-35000 adults would require care for DD and nearly $40 \%$ of them would be suffering from severe depression. Consistent with the findings of other studies conducted globally and in India, DD is more prevalent in the productive (30-59year) age group and is relatively high among females. ${ }^{15} 34363844-47$ Mental disorders, including depression, lead to diminished productivity at work and reduced rates of labour participation. ${ }^{19} 48$ Consequently, with a higher prevalence in the productive population, DD in India is likely to significantly affect the country's economy, and the burden is likely to be enhanced by the associated healthcare costs.

Association between urbanisation and depression has been inconsistent in the literature. Meta-analysis of Indian psychiatric studies ${ }^{15}$ and a similar analysis of the studies conducted in high income countries report significantly increased risk of depression/mood disorder in urban when compared with rural area. ${ }^{49}$ Lim et al observed that the prevalence of depression in rural settings $(13.0 \%)$ was lower than in urban settings $(17.7 \%)$, however, the difference was not statistically significant. ${ }^{29}$ Similarly, a review of Indian studies observed no such difference in prevalence of depression between urban and rural areas. ${ }^{16}$ In the NMHS, cities with population $>1$ million $(5.17 \%)$ had statistically significant higher prevalence of current DD, when compared with cities with population $<1$ million $(1.90 \%)$ and rural area $(2.15 \%)$. The prevalence of current DD was somewhat similar in cities with population $<1$ million $(1.90 \%)$ and rural area $(2.15 \%)$. These findings suggest that mega cities/cities with population $>1$ million may have a higher influence and association with occurrence of depression compared with smaller cities and rural area. Diverse factors broadly included under urban physical, social, cultural, economic and macro-micro environmental factors like concentration of poverty, changes in the family structure, social isolation and loneliness, economic stress, work-life imbalance, substance use and others are associated with urban life patterns, which in turn might set a platform for higher prevalence of mental disorders. ${ }^{50-52}$ As a significant number of people in India, ${ }^{53}$ Asia, Africa and other low to middle income countries will be residing in urban areas by $2030,{ }^{54}$ the burden of DDs will be significant in the absence of appropriate interventions and continuing urbanisation. Considering this, countries in these regions should develop and implement urban-specific strategies (under their health, mental health, NCD and all other socioeconomic welfare programmes) to develop an integrated approach to reduce the burden of DD.
The National Urban Health Mission in India provides an opportunity to develop such approaches for implementing evidence-based promotive and curative services, specially aimed at vulnerable segments of the population.

Depression is a disabling condition, leading to difficulties in work and carrying out household tasks. ${ }^{11} 1255$ It produces much greater decrements in health when compared with other chronic diseases. ${ }^{3}$ In 2010, major depressive disorder was the 11th and 6th leading contributor to global disability-adjusted life years (DALYs) and years lived with disability (YLDs), respectively. ${ }^{33}$ In India, the DALY rates for DD increased significantly between 1990 and 2016, and DD featured in the top 10 causes of YLD in $2016 .{ }^{56}$ In the present study, nearly one-fifth of the DD-affected individuals reported significant difficulties in activities of daily life. This assumes greater significance considering the treatment gap of almost $80.0 \%$ for DD in India, which is in concordance with other Indian studies. ${ }^{364657}$ Low perceived need, attitudinal barriers (desire to handle the problem on one's own) and stigma associated with mental illness are the major barriers to help seeking and staying in treatment among individuals with common mental disorders worldwide. ${ }^{58}$ In addition, scarce mental health resources with inequitable distribution and limited reach, increasing cost of care contribute equally to high treatment gap for mental illness in India. ${ }^{59}$ DD entails substantial disability, and untreated DD can significantly affect the individual's ability to lead a socially and economically productive life. Low income and middle income countries, where the treatment gap is high and mental health resource is scarce, ${ }^{61}$ should strengthen their health system on priority to expand services, increase coverage and improve quality of care for individuals with DD. Integrating care for DD within the primary healthcare, using community health workers to deliver the care and improving the number and quality of mental health-related human resources in the country will contribute to the reduction of treatment gap for DD. ${ }^{62}$

Disability and cost of care associated with depression impose considerable economic burden on the family. Chisholm et $\mathrm{l}^{63}$ estimated INR 700 per month ( 10 US\$) as the cost (healthcare and patient/family cost) of care for depression and anxiety. ${ }^{63}$ In the NMHS, families of persons with current DD on an average spent INR 1500 per month ( 23 US\$) towards care of the affected individual. The cost of care-related analysis was undertaken on individuals diagnosed exclusively with current DD (considering the fact that nearly half of the individuals with current DD had other co-occurring mental disorder), and intangible costs were not accounted for. Thus, NMHS underestimates the actual cost of care involved at the family level for managing DD among adults in India. Despite this limitation, NMHS reveals that the cost of care associated with DD is nearly one-sixth of the household income (median monthly household income among NMHS surveyed households being INR 9000 ( 137 US\$)), and this could have devastating effect on the family. Additionally, in the absence of state-sponsored or self-paid 
insurance coverage, DD could drive poor households to economic crisis, setting up a vicious cycle of poverty and mental disorder as observed by Patel and Kleinman ${ }^{64}$. This also has to be viewed against the background that individuals belonging to lowest income quintile households have significantly increased risk of DD (table 2). Sub-Saharan Africa and South Asia have world's highest proportion of people living in poverty. ${ }^{65}$ Hence, increasing investments towards mental healthcare in these regions would facilitate their attainment of SDG goals particularly SDG-goal 1 , that is, eradicating poverty in all its form everywhere.

This survey is not without limitations. NMHS was planned to be undertaken in a phase-wise manner, and phase I study included only 12 states. However, the 12 states were selected such that they were representative of different regions with diverse ethnicity and varied cultural characteristics. Hence, results of NMHS are likely to be nationally representative. Second, large cities of India with population of more than 10 million (metropolises) were not included in this survey. Since it was recognised that metropolises require different methodology, they would be surveyed in NMHS phase II (in Progress). Phase III will cover the remaining states of India. Finally, children $<13$ years were not included in NMHS due to lack of clear understanding of mental disorders from a population perspective and absence of suitable and culture-specific instruments. However, on pilot basis, adolescents aged 13-17 years were assessed for mental morbidity including depressive episode in four states of India to aid development of appropriate methodologies for future studies.

The NMHS data provide ample evidence to recognise DD as a major public health problem in India. This is a clarion call for all the concerned stakeholders to scale up mental health services at different levels of the healthcare delivery system under the NMHP in India and strengthen its implementation arm, the District Mental Health Programme, with a specific focus on DD. Evidence-based packages of services ${ }^{18}$ including pharmacological and non-pharmacological treatments that are acceptable and affordable should be made accessible to all. DD is prevalent in all age groups and is more often than not, associated with NCDs, suicide and substance use disorders. This underscores the need for integrating care for DD within other relevant national health programmes. ${ }^{9}$ Interventions to promote mental health spanning across health and other related sectors should be effectively implemented to substantially reduce the burden of DD. In terms of absolute numbers, India would contribute considerably to the global burden of depression. Sustainable, broad-based and integrated programmes for DD that resonate with National Mental Health Policy ${ }^{20}$ and WHO Mental Health Gap Action Programme ${ }^{66}$ will enable India and other countries to progress towards Sustainable Development Goals (SDG) 2030.

\section{Author affiliations}

${ }^{1}$ Department of Epidemiology, Centre for Public Health, National Institute of Mental Health and Neuro Sciences, Bangalore, Karnataka, India
${ }^{2}$ Department of Epidemiology, Centre for Public Health, National Institute of Mental Health and Neuro Sciences, Bangalore, Karnataka, India

${ }^{3}$ Department of Psychiatry, National Institute of Mental Health and Neuro Sciences, Bangalore, Karnataka, India

${ }^{4}$ Department of Epidemiology, Centre for Public Health, National Institute of Mental Health and Neuro Sciences, Bangalore, Karnataka, India

${ }^{5}$ Department of Psychiatry, National Institute of Mental Health and Neuro Sciences, Bangalore, Karnataka, India

${ }^{6}$ Department of Psychiatry, National Institute of Mental Health and Neuro Sciences, Bangalore, Karnataka, India

${ }^{7}$ Department of Epidemiology, Centre for Public Health, National Institute of Mental Health and Neuro Sciences, Bangalore, Karnataka, India

${ }^{8}$ Department of Community and Family Medicine, All India Institute of Medical Sciences, Bhopal, Madhya Pradesh, India

${ }^{9}$ Department of Psychiatry, Government Medical College and Hospital, Chandigarh, India

${ }^{10}$ Department of Psychiatry, King George's Medical University, Lucknow, Uttar Pradesh, India

${ }^{11}$ Department of Psychiatry, Central Institute of Psychiatry, Ranchi, Jharkhand, India ${ }^{12}$ Department of Psychiatry, Lokopriya Gopinath Bordoloi Regional Institute of Mental Health, Tezpur, Assam, India

${ }^{13}$ Department of Psychiatry, Regional Institute of Medical Sciences, Imphal, Manipur, India

${ }^{14}$ Department of Psychiatry, All India Institute of Medical Sciences, Raipur,

Chhattisgarh, India

${ }^{15}$ Department of Psychiatry, Sawai Man Singh Medical COllege, Jaipur, Rajasthan, India

${ }^{16}$ Department of Psychiatry, Institute of Mental Health, Kolkata, West Bengal, India

${ }^{17}$ State Nodal Officer, Mental Health Program, Chennai, Tamil Nadu, India

${ }^{18}$ Department of Psychiatry, Government Medical College, Surat, Gujarat, India

${ }^{19}$ Department of Psychiatry, Institute of Mental Health and Neuro Sciences, Kozhikode, Kerala, India

Acknowledgements Team NMHS is extremely thankful to the Ministry of Health and Family Welfare, Government of India, for its financial support in conducting the survey. We are immensely thankful to the guidance from members of the National Technical Advisory group and National Expert Panel. Our sincere thanks to NMHSNIMHANS team (http://indianmhs.nimhans.ac.in/Docs/Summary.pdf), NMHS state collaborators and their respective state government officials for their valuable participation at different stages of NMHS implementation. We wish to place on record our sincere gratitude to all the individuals and their family members across surveyed states for all the cooperation in the conduct of National Mental Health Survey.

Collaborators NMHS collaborators group: Lokesh Kumar Singh, Sonia Pereira Deuri, Mousumi Krishnatreya, Vijay Gogoi, Sobhana H, Saumik Sengupta, Indrajeet Banerjee, Sameer Sharma (Lokopriya Gopinath Bordoloi Regional Institute of Mental Health, Tezpur, Assam), Anjan Kumar Giri (All India Institute Of Medical Sciences, Raipur, Chhatisgarh), Abhay Bhaskar Kavishvar, Kamlesh Rushikray Dave, Naresh T. Chauhan (Government Medical College, Surat, Gujarat) Vinod K Sinha, Nishanth Goyal (Central Institute of Psychiatry, Ranchi, Jharkhand) Jayakrishnan Thavody, Anish PK, Thomas Bina (Institute of Mental Health And Neuro Sciences, Kozhikode, Kerala) Abhijit P. Pakhare, Pankaj Mittal, Sukanya Ray (All India Institute of Medical Sciences, Bhopal, Madya Pradesh) Rajni Chatterji (Bhopal Memorial Hospital and Research Centre, Bhopal, Madhya Pradesh) Brogen Singh Akoijam, Heramani Singh, Gojendro, Priscilla Kayina, Roshan Singh L (Regional Institute of Medical Sciences, Imphal, Manipur) Subhash Das, Sonia Puri, (Government Medical College and Hospital, Chandigarh) Rohit Garg (Government Medical College and Hospital, Patiala, Punjab) Amita Kashyap, Yogesh Satija, Kusum Gaur, Divya Sharma (Sawai Man Singh Medical College, Jaipur, Rajasthan) Sathish R V (Tamil Nadu Health Systems Project, Tamil Nadu) Selvi M (M.S. Chellamuthu Trust, Madurai, Tamil Nadu) Krishnaraj (National Health Mission-Tamil Nadu), Singh SK, Vivek Agarwal, Eesha Sharma, Sujit K Kar (King George's Medical University, Lucknow, Uttar Pradesh), Raghunath Misra, Rajashri Neogi, Debasish Sinha, Soumyadeep Saha, Ajoy Halder (Institute of Psychiatry, Kolkata, West Bengal), Pradeep Banandur S, Gautham Melur Sukumar, Subbakrishna D K, Thennaarasu, Marimuthu P, Binu Kumar B, Sanjeev Jain, Janardhan Reddy Y C, Jagadisha T, Sivakumar P T, Prabhat Kumar Chand, Muralidharan K, Senthil Reddi, Naveen Kumar C, Krishna Prasad M, Jaisoorya T S, Janardhanan C N, Mahendra Prakash Sharma, Suman L N, Paulomi S, Keshav Kumar, Manoj Kumar Sharma, Manjula M, Poornima Bhola, Roopesh B N, Thomas Kishore M, Veena S, Aruna Rose Mary K, Nitin Anand, Shobha Srinath, 
Satish Chandra Girimaji, John Vijayasagar K, Sekar Kasi, Muralidhar D, Dhanasekara Pandian R, Ameer Hamza, Janardhana N, Aravinda Raj E, Gobinda Majhi (National Institute of Mental Health and Neuro Sciences, Bangalore).

Contributors GG, MV, VB, GNR and SA contributed to the conception of the study. GG, MV, VB, GNR, SA, BAA, SL, AMK, CBS, DPK, DR, KP, LSR, LKS, PS, PKS, RC, RYM and STM contributed to the design and facilitated acquisition of data for the study. BAA and GG carried out the statistical analysis. GG and BAA developed first draft of the manuscript, which was critically revised for important intellectual content by all authors (MV, VB, GNR, SA, SL, AMK, CBS, DPK, DR, KP, LSR, LKS, PS, PKS, RC, RYM and STM), who approved the final version. GG and BAA are guarantors. The corresponding author (GG) attests that all listed authors meet authorship criteria and that no others meeting the criteria have been omitted. The NMHS collaborators group facilitated data collection in 12 states of India.

Funding This research was funded by the Ministry of Health and Family Welfare, Government of India.

Competing interests The funders were not actively involved in the research process at any stage. Researchers had the independence from funders and that all authors, external and internal, had full access to all of the data (including statistical reports and tables) in the study and takes responsibility for the integrity and accuracy of the data. The views expressed in this publication are those of the authors and not necessarily those of the funding agencies.

Patient consent for publication Not required.

Ethics approval This study was approved by the NIMHANS Institution Ethics Committee vide its letter No. NIMHANS/D0/97th IEC/2015 dated 29 April 2015. In addition, each of the study sites obtained separate ethics approval from their individual institutional ethical committees. All participants gave informed consent before taking part in the study. 'We attest that we have obtained appropriate permissions and paid any required fees for use of copyright protected materials.

Provenance and peer review Not commissioned; externally peer reviewed. Data sharing statement № additional data available.

Open access This is an open access article distributed in accordance with the Creative Commons Attribution Non Commercial (CC BY-NC 4.0) license, which permits others to distribute, remix, adapt, build upon this work non-commercially, and license their derivative works on different terms, provided the original work is properly cited, appropriate credit is given, any changes made indicated, and the use is non-commercial. See: http://creativecommons.org/licenses/by-nc/4.0/.

\section{REFERENCES}

1. Murray CJ, Barber RM, Foreman KJ, et al. Global, regional, and national disability-adjusted life years (DALYs) for 306 diseases and injuries and healthy life expectancy (HALE) for 188 countries, 1990-2013: quantifying the epidemiological transition. Lancet 2015;386:2145-91.

2. GBD 2015 Disease and Injury Incidence and Prevalence Collaborators. Global, regional, and national incidence, prevalence and years lived with disability for 310 diseases and injuries, 19902015: a systematic analysis for the Global Burden of Disease Study 2015. Lancet 2016;388:1545-602.

3. Moussavi S, Chatterji S, Verdes E, et al. Depression, chronic diseases, and decrements in health: results from the World Health Surveys. Lancet 2007;370:851-8.

4. World Health Organization. Depression and other common mental disorders: global health estimates. 2017. http://apps.who.int/ iris/bitstream/10665/254610/1/WHO-MSD-MER-2017.2-eng.pdf (Accessed 2017 Oct 5).

5. Steel Z, Marnane C, Iranpour C, et al. The global prevalence of common mental disorders: a systematic review and meta-analysis 1980-2013. Int J Epidemiol 2014;43:476-93.

6. Demyttenaere K, Bruffaerts R, Posada-Villa J, et al. Prevalence, severity, and unmet need for treatment of mental disorders in the World Health Organization World Mental Health Surveys. JAMA 2004;291:2581-90.

7. Mathers CD, Loncar D. Projections of global mortality and burden of disease from 2002 to 2030. PLoS Med 2006;3:e442.

8. Allen J, Marmot M. Social determinants of mental health. 2014. http://apps.who.int/iris/bitstream/10665/112828/1/9789241506809_ eng.pdf?ua=1 (Cited 25 Jul 2018).

9. World Health Organization. Depression in India, Lets talk. http://www. searo.who.int/india/depression_in_india.pdf (Accessed 5 Oct 2017).
10. Mitchell AJ, Vaze A, Rao S. Clinical diagnosis of depression in primary care: a meta-analysis. The Lancet 2009;374:609-19.

11. Ansseau M, Fischler B, Dierick M, et al. Socioeconomic correlates of generalized anxiety disorder and major depression in primary care: the GADIS II study (Generalized Anxiety and Depression Impact Survey II). Depress Anxiety 2008;25:506-13.

12. Olfson M, Fireman B, Weissman MM, et al. Mental disorders and disability among patients in a primary care group practice. Am J Psychiatry 1997;154:1734-40.

13. Gururaj G, Girish N, Issac MK. Mental, Neurological and Substance use disorder: Strategies towards a systems approach. Burden of Disease in India, National Commission on Macroeconomics and health; Ministry of Health and Family Welfare, Government of India, New Delhi. 2005. http://www.who.int/macrohealth/action/NCMH Burden\%20of\%20disease_(29\%20Sep\%202005).pdf (Accessed 5 Oct 2017).

14. Math SB, Chandrashekar CR, Bhugra D. Psychiatric epidemiology in India. Indian J Med Res 2007;126:183-92.

15. Reddy VM, Chandrashekar CR. Prevalence of mental and behavioural disorders in India: a meta-analysis. Indian J Psychiatry 1998;40:149-57.

16. Ganguli HC. Epidemiological findings on prevalence of mental disorders in India. Indian J Psychiatry 2000;42:14-20.

17. World Health Organization. Mental health: new understanding, new hope. repr. Geneva: World Health Organization, 2002:178.

18. Patel V, Simon G, Chowdhary N, et al. Packages of care for depression in low- and middle-income countries. PLoS Med 2009;6:e1000159.

19. Mnookin S. Out of the shadows, Making mental health a global developmental priority. World bank group and World health Organisation. http://documents.worldbank.org/curated/en/ 270131468187759113/pdf/105052-WP-PUBLIC-wb-backgroundpaper.pdf (Accessed 5 Oct 2017).

20. New Pathways New Hope. National mental health policy of India. Ministry of Health and family Welfare, Government of India. 2014. https://www.nhp.gov.in/sites/default/files/pdf/national\%20mental\% 20health\%20policy\%20of\%20india\%202014.pdf (Accessed 5 Oct 2017).

21. National Mental Health Programme. National Institute of Health \& Family Welfare. http://www.nihfw.org/NationalHealthProgramme/NATI ONALMENTALHEALTHPROGRAMME.html (Accessed 5 Oct 2017).

22. Gururaj G, Varghese M, Benegal V, et al. National Mental Health Survey of India, 2015-16: Prevalence, patterns and outcomes. Bengaluru: National Institute of Mental Health and Neuro Sciences, NIMHANS Publication, 2016:129.

23. Gururaj G, Varghese M, Benegal V, et al. National Mental Health Survey of India, 2015-16: Summary. Bengaluru: National Institute of Mental Health and Neuro Sciences, NIMHANS Publication, 2016:128.

24. Pradeep BS, Gururaj G, Varghese M, et al. National Mental Health Survey of India, 2016 - Rationale, design and methods. PLoS One 2018;13:e0205096.

25. Census of India Website. Office of the Registrar General \& Census Commissioner, India. http://www.censusindia.gov.in/2011census/ population_enumeration.html (Accessed 25 Jul 2018).

26. Sheehan DV, Lecrubier Y, Sheehan $\mathrm{KH}$, et al. The Mini-International Neuropsychiatric Interview (M.I.N.I.): the development and validation of a structured diagnostic psychiatric interview for DSM-IV and ICD10. J Clin Psychiatry 1998;59:34-57.

27. Sheehan DV, Harnett-Sheehan K, Raj BA. The measurement of disability. Int Clin Psychopharmacol 1996;11(Suppl 3):89-95.

28. IBM Corp. IBM SPSS Statistics for Windows, Version 22.0, Armonk, NY: IBM Corp. 2013.

29. Lim GY, Tam WW, Lu Y, et al. Prevalence of Depression in the Community from 30 Countries between 1994 and 2014. Sci Rep 2018;8:1-10.

30. Andrade L, Caraveo-Anduaga JJ, Berglund P, et al. The epidemiology of major depressive episodes: results from the International Consortium of Psychiatric Epidemiology (ICPE) Surveys. Int J Methods Psychiatr Res 2003;12:3-21.

31. Kessler RC, Bromet EJ. The epidemiology of depression across cultures. Annu Rev Public Health 2013;34:119-38.

32. Bromet E, Andrade LH, Hwang I, et al. Cross-national epidemiology of DSM-IV major depressive episode. BMC Med 2011;9:90.

33. Ferrari AJ, Somerville AJ, Baxter AJ, et al. Global variation in the prevalence and incidence of major depressive disorder: a systematic review of the epidemiological literature. Psychol Med 2013;43:471-81.

34. Ferrari AJ, Charlson FJ, Norman RE, et al. The epidemiological modelling of major depressive disorder: application for the Globa Burden of Disease Study 2010. PLoS One 2013;8:e69637. 
35. Üstün TB, Ayuso-Mateos JL, Chatterji S, et al. Global burden of depressive disorders in the year 2000. British Journal of Psychiatry 2004; 184:386-92.

36. Sagar R, Pattanayak RD, Chandrasekaran R, et al. Twelve-month prevalence and treatment gap for common mental disorders: Findings from a large-scale epidemiological survey in India. Indian $J$ Psychiatry 2017;59:46.

37. Deswal BS, Pawar A. An epidemiological study of mental disorders at pune, maharashtra. Indian J Community Med 2012;37:116-21.

38. Sathyanarayana Rao TS, Darshan MS, Tandon A, et al. Suttur study: an epidemiological study of psychiatric disorders in south Indian rural population. Indian J Psychiatry 2014;56:238-45.

39. Patel V. Cultural factors and international epidemiology. Br Med Bull 2001;57:33-45.

40. Raguram R, Weiss MG, Keval $\mathrm{H}$, et al. Cultural dimensions of clinical depression in Bangalore, India. Anthropol Med 2001;8:31-46.

41. Rai D, Zitko P, Jones K, et al. Country- and individual-level socioeconomic determinants of depression: multilevel cross-national comparison. Br J Psychiatry 2013;202:195-203.

42. TB India. Revised National Tuberculosis Control Programme, Annual status report. Central TB Division, Directorate General of Health Services, Ministry of Health and Family Welfare, Government of India. 2017. http://tbcindia.gov.in/WriteReadData/TB\%20India\%202017. pdf (Accessed 5 Oct 2017).

43. India HIV Estimations. National AIDS Control Organization \& National Institute of Medical Statistics, ICMR Ministry of Health \& Family Welfare Government of India[Internet]. 2015 http://www.naco.gov. in/sites/default/files/India\%20HIV\%20Estimations\%202015.pdf (Accessed 5 Oct 2017).

44. Mathias K, Goicolea I, Kermode M, et al. Cross-sectional study of depression and help-seeking in Uttarakhand, North India. BMJ Open 2015;5:e008992.

45. Poongothai S, Pradeepa R, Ganesan A, et al. Prevalence of depression in a large urban South Indian population--the Chennai Urban Rural Epidemiology Study (CURES-70). PLoS One 2009;4:e7185.

46. Shidhaye R, Gangale S, Patel V. Prevalence and treatment coverage for depression: a population-based survey in Vidarbha, India. Soc Psychiatry Psychiatr Epidemiol 2016;51:993-1003.

47. Jonas JB, Nangia V, Rietschel M, et al. Prevalence of depression, suicidal ideation, alcohol intake and nicotine consumption in rural Central India. The Central India Eye and Medical Study. PLoS One 2014;9:e113550.

48. Lerner D, Adler DA, Rogers WH, et al. Work performance of employees with depression: the impact of work stressors. Am J Health Promot 2010;24:205-13.

49. Peen J, Schoevers RA, Beekman AT, et al. The current status of urban-rural differences in psychiatric disorders. Acta Psychiatr Scand 2010;121:84-93.
50. Gruebner O, Rapp MA, Adli M, et al. Cities and Mental Health. Dtsch Ärztebl Int. 2017;114:121-7.

51. Nambiar D, Razzak J, Afsana K, et al. Mental illness and injuries: emerging health challenges of urbanisation in South Asia. BMJ 2017;357:j1126.

52. Srivastava K. Urbanization and mental health. Ind Psychiatry $J$ 2009;18:75-6.

53. Shirish S, Ireena V, Richard D, et al. India's urban awakening: building inclusive cities, sustaining economic growth. Mckinsey Global Institute. 2010. https://sumnetindia.files.wordpress.com/ 2011/11/mckinsey_india_urbanization_fullreport.pdf (Accessed 5 Oct 2017).

54. United Nations, Department of Economic and Social Affairs, Population Division. World urbanization prospects: the 2014 revision. 2014.

55. Sanderson K, Andrews G. Prevalence and severity of mental healthrelated disability and relationship to diagnosis. Psychiatric Services 2002;53:80-6.

56. Dandona L, Dandona R, Kumar GA, et al. Nations within a nation: variations in epidemiological transition across the states of India, 1990-2016 in the Global Burden of Disease Study. The Lancet 2017;390:2437-60.

57. Raban MZ, Dandona R, Kumar GA, et al. Inequitable coverage of non-communicable diseases and injury interventions in India. Natl Med J India 2010;23:267-73.

58. Andrade LH, Alonso J, Mneimneh Z, et al. Barriers to mental health treatment: results from the WHO World Mental Health surveys. Psychol Med 2014;44:1303-17.

59. Saxena S, Thornicroft G, Knapp M, et al. Resources for mental health: scarcity, inequity, and inefficiency. Lancet 2007;370:878-89.

60. Kaur R, Pathak RK. Treatment Gap in Mental Healthcare. Econ Polit Wkly 2015;52:7-8.

61. Patel V. The future of psychiatry in low- and middle-income countries. Psychol Med 2009;39:1759-62.

62. Patel V, Maj M, Flisher AJ, et al. Reducing the treatment gap for mental disorders: a WPA survey. World Psychiatry 2010;9:169-76

63. Chisholm D, Sekar K, Kumar KK, et al. Integration of mental health care into primary care. Demonstration cost-outcome study in India and Pakistan. Br J Psychiatry 2000;176:581-8.

64. Patel V, Kleinman A. Poverty and common mental disorders in developing countries. Bull World Health Organ 2003;81:609-15.

65. World Bank. World Development Indicators 2017. Washington, DC: World Bank, 2017.

66. WHO. mhGAP Mental Health Gap Action Programme [Internet] WHO. http://www.who.int/mental_health/evidence/mhGAP/en/ (Accessed 25 Jul 2018). 